\title{
Many voices: Building a biblioblogosphere in Ireland
}

\author{
Abstract: \\ Blogging has been associated with the Library and Information Science (LIS) community for \\ some time now. Libfocus.com is an online blog that was founded in 2011. Its goal was to create \\ a communal communication space for LIS professionals in Ireland and beyond, to share and \\ discuss issues and ideas. The content of the blog is curated by an editorial team, and features \\ guest bloggers from across all sectors and experience levels. Using a qualitative methodological \\ approach, open-ended surveys were conducted with twelve previous guest bloggers, in order to \\ explore how and why Irish-based LIS professionals choose to communicate through blogging. It \\ is hoped that this evidence will provide a greater understanding of both the value and \\ effectiveness of blogging as an outreach and communication tool within the profession, helping \\ both libraries and librarians to be more strategic in their use of it as a medium.
}

\section{Introduction}

The librarian has always been closely linked with communication (Meakin, 1981) - connecting people and information, individuals with ideas, and learners with knowledge. The nature of this communication has changed over time as new technologies and channels have emerged and developed. Today, librarians see the use of web 2.0 tools as a routine part of library outreach and communications (Tripathi \& Kumar, 2010; Kim \& Abbas, 2010). The emergence and use of blogs in particular, is of interest for many reasons, including monitoring "how communication methods are used in libraries and by librarians" (Lee \& Bates, 2007, p. 649). It is this aspect which forms the focus of this research.

Libfocus.com is an online group blog that was founded in 2011. It originated with the goal of creating a communal communication space for LIS professionals primarily based in Ireland, but 
also beyond, to share and discuss library and information management issues and ideas at a time when blogging remained relatively incipient amongst librarians in Ireland. The content of the blog is curated by an editorial team, with blog posts contributed by this team, as well as guest bloggers from across all sectors and experience levels. Many of these bloggers have never previously written formally for publication. Consequently the blog has played a key role in helping to foster and develop the relatively nascent culture of written online communication within the LIS profession in Ireland.

This research adopts a distinctly Irish focus. It looks at how the situation in Ireland relates to, and interfaces with, the existing debate taking place within the broader international context. Lee \& Bates' (2007) study provides a seminal analysis of blogging in the Irish LIS community. However, the growth and rise of new technologies and social media has continued apace since then. Today's environment offers many new communication channels and formats that challenge traditional blogging. Informed by Lee and Bates' (2007) results, we re-explore and revisit the blogging landscape in Ireland to examine whether the use of blogging has changed over this intervening period in consonance with the widespread explosion of digital social media and networking. The aim is to unpack and explore the motivations behind and attitudes towards the use of blogging as a communication tool and to examine its effectiveness or otherwise.

\section{The emergence and role of blogging}

The "biblioblogosphere" (Schneider, 2005) has been a feature of the library landscape for over a decade now. However the use of blogs by both librarians and libraries goes back even further than that (Embrey, 2002; Fichter, 2003). In this time, the popularity of blogs has waxed and waned, but they still retain a strong presence within academic and library sectors (Tripathi \& Kumar, 2010; Kim \& Abbas, 2010). What we have perhaps witnessed is a by-product of the 
natural maturing of social media and networking, as its use has become more prevalent, diversified and sophisticated. Notwithstanding this, blogging has cemented a place within this crowded landscape as a platform for both dissemination and critical dialogue, with one Irish academic institution specifically describing the purpose of their blog as being for “communications and interaction" (Lee \& Bates, 2007, p. 657).

There are two streams through which blogging has been used as a communication channel (Trivedi, 2010). Firstly, it has been adopted by libraries to publicise and promote their services at an institutional level or as an internal channel of communication, and secondly, by individual librarians to interact professionally on a personal level. This study primarily relates to the latter. However, as in many cases librarians blog about work-related projects or initiatives in order to promote their institutions, and indeed also maintain institutional blogs. Any thorough discussion of blogging inevitably touches on the role and use of the former.

\section{Library (institutional) blogs}

An institutional or external library blog can be used to communicate information in many ways, most notably as "a marketing tool which has the potential to showcase library collections and the professional expertise that librarians offer to their faculty" (Mclntyre \& Nicolle, 2008, p. 688). This kind of library blogging has been a feature at institutional level in Ireland for some time now, with a number enjoying significant longevity, such as the Hardiblog (http://hardimanlibrary.blogspot.ie/) maintained by the James Hardiman Library, NUI Galway, first established in 2007. Whilst some blogs have also died out during this period, in recent times a growing number of niche blogs have appeared. For instance Sir Henrys at University College Cork Library (https://sirhenrys2014.wordpress.com) , or Tales of Mystery and Pagination (https://mysterypagination.wordpress.com/) at Trinity College Dublin Library. These 
institutional blogs are often used as communication tools to promote unique and distinctive collections or services, such as special collections, events, and exhibitions.

\section{Librarian (personal and individual) blogs}

Personal blogs by their nature often offer individuals more flexibility and freedom in terms of what and how to communicate. In an international context, there are a number of long-running high profile personal library blogs such as http://www.librarian.net , http://letterstoayounglibrarian.blogspot.ie , https://agnosticmaybe.wordpress.com and http://librarianbyday.net. However, in Ireland personal library blogs have generally remained relatively under the radar until more recent times. This hesitance may partly reflect the findings of Lee \& Bates who noted that "the principal reason for not utilizing weblogs was that librarians did not consider weblogs as professional tools, while other factors included ... other methods of communication were preferred" (2007, p. 660). However, their use within MLIS and other professional qualification programmes, as well as initiatives such as the University of Limerick's 23 Things (http://ul23things.blogspot.ie) and the Library Association of Ireland's Rudaí23 http://rudai23.blogspot.ie , and the student run and oriented http://slipireland.blogspot.ie/ has marked a slow yet steady increase in the number of librarian blogs, particularly among new and emerging professionals, reflecting the oft-cited benefits of blogging as a tool for reflective practice and CPD (Hall \& Davison, 2007).

\section{The why and the wherefore?}

At an individual or personal level, it appears that even from the earliest days of blogging, librarians have perceived blogging as a beneficial tool for communicating and sharing knowledge and best practice with colleagues. Stephens examines early-adopters in the world of librarian blogging, describing the "pragmatic biblioblogger" as "a librarian who is incorporating blogging as a means to share opinion and information. Sharing procedures and practices allows 
this librarian to give back, make life easier for other professionals, and serve the profession" (2008, p.336). Moreover, Stephens finds that it is "the opportunity to comment, to connect, and to create" that underpins the motivations of the many librarians who do blog $(2008$, p. 338).

At an institutional level, blogs can be effective tools to help establish the all-important marketing dialogue between the library and its diverse target audiences. They offer advantages by being easy to use, free, and immediate, and provide a channel to keep your customers up to date (Dowd et al., 2010, p. 84-85). New tools such as blogging present both opportunities and challenges for librarians and libraries however. As Adams observes, "many see the impact of these new technologies as a change in the mindset of librarians as much as a development of skills" (2013, p. 671) and those who embrace it, often reap rewards in terms of marketing and promotion, relationship-building and exposure for library services and staff (Stover, 2007). Stefanone and Jang $(2008,131)$ state that "as a communication channel, blogs allow their authors to disseminate information to their social networks easily". Librarians also believe that blogging is an excellent way to market their library and its resources (Draper \& Turnage, 2008 18). In addition, blogging offers other benefits by providing an outlet for creativity, the simplicity of the tools involved, and notably the potential to increase "professional profile" (Lee \& Bates, 2007, p. 659). These advantages apply to both institutions and individuals.

In spite of such potential gains, the difficulties attached to maintaining blogs are frequently highlighted, especially the "serious time commitment", the "pressure" to update information alongside other existing workloads, and the need for it to be managed "by someone who believes in interaction" (Lee \& Bates, 2007, p. 657). Many of these same factors are echoed in international experiences (Mclntyre \& Nicolle, 2008). It is possible that these challenges have hindered the use of blogging at institutional level across libraries in Ireland, with the budgetary and staffing constraints experienced in recent years precipitating the curtailment of nonessential or non-core services. As personal blogging is undertaken in an individual's own free 
time, there are perhaps more opportunities for librarians to engage with the communication channel in this way.

\section{Methodology}

The study was informed by an interpretative phenomenological analysis (IPA) approach with an idiographic focus ${ }^{1}$, in seeking to explore why and how individual librarians in Ireland blog from their own perspective. IPA was originally proposed by Jonathan Smith (1996) in application to the field of psychology. It has only recently been co-opted by the LIS community as one way of effectively exploring the experience of information professionals (VanScoy and Evenstad, 2015, p. 338). For the purpose of this study, IPA, with its emphasis on the idiographic (individual) experience, is considered an appropriate method for mapping personal knowledge, subjectivity and interpretation of professional LIS blogging.

A qualitative methodology was utilised in order to capture a richer insight into the potentially varied experiences and motivation of bloggers. An in-depth, structured survey with open-ended questions was distributed via email to a sample of twelve participants. The exploratory and fully open nature of the questions as well as the detailed length of the survey, combined with, in a number of cases, subsequent interaction and follow-up, closely matches the approach of an email interview. The choice of sample size reflects the findings of Guest et al. (2006) who estimate that a sample of approximately twelve is typically sufficient for interview studies to identify emergent themes.

The qualitative surveys were carried out electronically via email and collected using Google Forms, largely for practical and logistical reasons (geographical and time constraints). Whilst

\footnotetext{
${ }^{1}$ Interpretative phenomenological analysis (IPA) centres on the analysis of speech/language/dialogue, typically obtained through interview and discussions. IPA attempts to uncover the thought processes that underpin that language (McQueen and Knussen, 2002, p. 202).
} 
face to face interviews may have been preferable to provide the opportunity to tease out certain aspects even further, Meho (2006, p. 1293) finds that interviews conducted via email "can be employed quickly, conveniently, and inexpensively and can generate high-quality data when handled carefully". The participants were selected from a random list of all guest Libfocus.com bloggers who were engaged in academic or research libraries at the time of their posting(s).The aim was to gain a representative spread across institutions and roles. A number of participants were also responsible for maintaining or contributing to institutional or external blogs in addition to blogging at a personal level.

In terms of data analysis, a directed content analysis approach was adopted (Hsieh \& Shannon, 2005), guided by the existing theory and research in the area. An initial list of 'a priori' codes were derived from the key themes and issues identified during the literature review process. These included: communication within the profession, communication outside the profession, marketing and promotion, information sharing for professional development purposes, challenges, and benefits. A number of further emergent codes were generated and refined during the coding process. Each survey response was separately coded by two individuals, who then convened to compare and discuss their findings, with percent agreement used to ensure sufficient intercoder reliability.

\section{Results and Discussion}

From the analysis of the survey responses a number of recurring themes emerged relatively early. This was indicative that many of the aims, motivations, benefits and challenges associated with blogging represent a shared experience. 


\section{Communication within the profession}

With respect to individual blogging motivations, communication within the profession tends to dominate. There are many reasons for this. One participant explains that they blog "within the library world because it is a recognised medium for us. It is targeted and you know your audience understands your perspective". This belief suggests that blogging is becoming more firmly recognised and understood within the profession in Ireland, and not just by those who may be engaged with, or interested in, emerging communication technologies. Blogging may even come to be seen as one of the de facto channels of communication in this respect, a venue for sharing items "that other librarians would be interested in". It is notable that it is also used by bloggers to advocate within the LIS community, in one case to "raise awareness and increase understanding about an issue: for example - open access." In this context, blogging may offer a valuable platform as a communication catalyst for highlighting and heightening key issues that require championing within the profession. A further response in support of this idea is the assertion by a respondent that content on Libfocus

"is fresh and uncensored. The blog doesn't shy away from controversial topics that we

as a profession need to consider such as the inappropriate use of people on unpaid work experience. Blogging gives a voice to library personnel in a more democratic, powerful and immediate way than perhaps even peer reviewed journals do."

Another post that caused disquiet was a critical review of a library conference. Other posts, such as those on Radical Librarianship, Library Induction, open access, special libraries and the role and direction of libraries and librarians always raise discussion.

\section{Communication outside the profession}

Whilst most participants viewed personal blogging as a channel for communicating within the profession in the first instance, those who do use it as a tool to communicate with library users 
or other stakeholders find it of real value. One respondent noted personal blogging can be useful in "documenting the type of work we do... by highlighting the continuous learning and professional development which takes place in the profession and to showcase the different types of librarianship which exist". In this sense, blogging helps to communicate the role, profile and visibility of a modern librarian to the outside world, breaking down stereotypes and traditional views. Indeed this is encapsulated by another blogger as "advocating for the role of librarians and dispelling stereotypes" in a "small way".

In contrast to individual blogs, institutional blogging is typically aimed at a wider audience, with one participant believing it enables her "to communicate with library users in an effective way.... institutional websites are quite static and blogs can be very flexible". However, there are also critical voices on the back of direct experience. One respondent raised the concern that the blog as a communication tool outside the profession was perhaps not as effective as other alternatives such as Linkedln and Twitter. This sentiment was backed up by another respondent who cited the value of both Facebook and Twitter.

\section{Knowledge sharing}

Continuous professional development, and in particular, communicating and sharing new information and knowledge across the profession, is highlighted as a key incentive by the majority of respondents, indicative that the motivations depicted in Stephens' "pragmatic biblioblogger" (2008) are still relevant today. This also resonates with Baxter et al's finding that "the fact that blogs are generally about producing content means that they are often associated with the notions of dialogue and information sharing" (2010, p. 518). This aspect was emphasised by one librarian who explained that "a key part of blogging for me is sharing knowledge. I think this is an important part of librarianship, imparting what we know to each 
other and learning from each other's experience". In this respect, it is clear that librarians want to communicate and share their expertise and learning to benefit colleagues and peers, as well as themselves.

The advantages in terms of communicating the latest developments and keeping current within the profession were flagged repeatedly, with blogging seen as a way of communicating "regular snapshots of what's going on in the profession", "a sense of what is happening in the library profession in Ireland and beyond" and "“finding out what the hot topics are in librarianship". The need for academic librarians in Ireland to reassess and adapt their skills continuously is clear within the literature (Corcoran and McGuinness, 2014), and it is evident that many librarians find blogging a valuable source of information in this respect.

Extending this idea further, many participants also referenced blogging as a key part of their "personal reflective practice", a means to "document learning" and a way of "reflecting on my professional progress". This indicates that communication may be a secondary goal in some contexts. Notwithstanding this, one blogger noted that they "find it most interesting to hear other professionals' reflections on their work and everyday experiences..." This may suggest that there is also real value attached to librarians sharing these personal, individual reflections on their everyday practice across the library community. Communicating this reflective practice to others allows the profession to benefit as well as the individual. This is perhaps one type of information that is almost uniquely communicated via blogging - and one of the key ways that the channel adds distinct value to the community and profession. 


\section{Marketing and Promotion}

Marketing, promotion and visibility were repeatedly alluded to, both from the perspective of building and promoting an individual professional profile, as well as showcasing librarians' skills and services to the outside world. With respect to the former, this can often help LIS professionals to network and communicate across sectors and even countries, with one participant noting that "blogging on Libfocus raises my visibility as a health science librarian to librarians working in different sectors to me... and internationally." This sentiment was echoed by several bloggers whose experience was that blogging was "wonderful for Irish visibility within the profession", often "creates a public persona" and can be "useful in terms of career progression". This experience resonates strongly with Lee \& Bates' finding that enhancing "professional profile" (2007, p. 659) was a key aspect attached to blogging.

The importance of marketing and promoting libraries, and their collections, expertise and services to our users is well documented (Mallon, 2013; Ratzek, 2011), and social media and networking tools have sparked myriad possibilities in this respect. As one participant noted: "there's no point to a library unless it's being used. Blogging and tweeting allow others to see different aspects of the library."

Showcasing collections and events using a blog has opened up new opportunities: "Many more schools and departments want to do different types of exhibitions and collaborate (with us) in different ways. This, is based on the fact that we blog on each exhibition we do." Moreover, the fluidity of the format allows libraries to be more responsive and flexible in how they promote and market services and collections (One respondent described how "blogs can be updated very easily (as opposed to institutional websites) and this is useful in terms of outreach". Another noted that the blog format is "crucial to raising the visibility of the library to our readers". 


\section{Networking, interaction and feedback}

Whilst blogging offers benefits as a one-way communication or broadcasting tool, the frequent use of blogging as a platform to stimulate interaction, feedback and engagement was also clear from the participants' responses. By facilitating communication and connection between professionals, blogging was seen by participants as a two-way "platform for discussion", a valuable way to "get feedback from colleagues and peers" and "to test ideas, to see how they are received". One librarian noted that by opening up communication across all library sectors, guest blog posts are particularly "useful for making connections with other librarians".

Blogging offers a broader canvas in many ways. It provides breathing space that longer-form narrative can explore and occupy, and consequently, the infrastructure necessary to potentially initiate and encourage dialogue and discussion at a deeper and more complex level. In contrast to the micro-blogging format of Twitter which is perhaps more popular in some respects, one respondent believes "the ability to add quite a long comment after a blog post is a good way to discuss an issue further without the limited word count". The notable sense of enjoyment from such interactions is articulated by one blogger who stated that "I love when someone comments on my blog".

Indeed, the importance of this networking and interaction effect is seen as crucial by some, with one blogger believing that "the real measure of blogging being effective is the amount a post is shared on Twitter or other social media, or feedback online and in person. If there is no response or feedback to blogging, its effectiveness as a communication tool is definitely reduced". The significance of two-way dialogue and communication is also highlighted by another blogger who used blogging "to test ideas, to see how they are received and if I think the feedback is positive on many levels I consider writing an article." This contrasts somewhat with Adams' view that a lack of interaction or engagement "does not necessarily undermine the 
effectiveness of a blog. Even where the tool is used to simply push content out, it can still provide a value, for example as a repository of information or as a news update" (2013, p. 672). Whilst the one-way broadcasting function of blogs is still an important means of communication and one that has worth, the responses from participants in this study suggest that both bloggers and readers will benefit most if there is interaction and communication in both directions.

\section{Challenges}

As the participants in the study were all already bloggers, some of the challenges that typically surface around the initial use of a new technology and learning how to set-up and maintain a blog (Baxter et al, 2010) were not an issue. However, it is striking that ten of the twelve participants all cited time pressures as a primary challenge associated with blogging. In this respect it appears that little has changed since Lee \& Bates study in 2007 when the "serious time commitment" associated with the activity was highlighted (p. 657). This raises some obvious questions. Whilst blogging clearly offers many benefits, are other channels perhaps more time-effective ways to communicate in terms of return on investment? How can blogging be made more efficient as a communication tool? Do we, as a profession, need to more formally recognise blogging as essential, and dedicate part of our workday to it, even at the expense of other activities?

Perhaps a group-blogging format, similar to Libfocus.com, may lessen this challenge for some of those who stated it was "difficult to find the time". The formation of collectives of several individuals working in particular sectors or in particular roles may help to spread the commitment and shoulder the workload of keeping blogs up to date and current. Indeed the creation of such blogging groups may even enhance interaction, dialogue and networking between bloggers and generate the "sense of community" that Baxter et al. contend is one of 
the key advantages of blogging (2010, p. 518). A pertinent example in support of this idea, is the Reference and User Services Association (RUSA) blog, Chasing Reference (chasingreference.com) - a collaborative blogging project initiated in 2012. Its aim is to bring together the experiences of professional librarians across the reference services domain. Barlow et al. (2013) acknowledge that professional conversations can be successfully stimulated through the community effect of this kind of shared blogging platform.

Social media is a competitive landscape where the adage of survival of the fittest often holds true. Whilst all participants listed examples of other social media tools they use to communicate, mainly Twitter, Facebook and Linkedln, it is notable that eight of the twelve participants still viewed blogging as either "important" or "very important" in communicating their message. This may be in part because different channels and tools work well in different contexts. This is not always to the detriment of blogging, and indeed can even complement and stimulate it; as one participant noted "I don't always have time to blog, but tweeting is a quick and easy way to stay engaged, communicate within the profession and sometimes even find ideas to get a longer blog post started.“

However, despite the emergence and growth of blogging by Irish LIS professionals in recent times, there may still be traces of hesitancy within some sectors. One blogger believes that "librarians perhaps do not see blogging as an essential part of their work but personally I think the Blog is crucial to raising the visibility of the library to our readers". From the responses of participants it appears that for those that do engage in blogging, the benefits are obvious and almost instantly felt. Perhaps it is only those who are not active bloggers themselves that remain unconvinced? It would seem that the equivocation articulated by some Irish librarians who did not consider blogs as "professional tools" in Lee \& Bates' study (2007), may still be in existence 
today. In this context, further research specifically targeting those who don't engage in blogging may provide further insight into the reasons behind this.

\section{Conclusion}

The responses from LIS professionals in this study suggest that blogging has retained, and perhaps even expanded, its value as a communication tool in recent years, despite finding itself under threat from new and evolving competitors. Its role as a mechanism for building and communicating a professional profile underlines the utility of the tool to new professionals in particular, who can potentially benefit from using the platform to highlight their own work and skills, as well as reaching out to a new network of colleagues and professionals. The rate of change in all areas of academic librarianship continues apace, and it is clear that librarians must evolve and adapt accordingly. By offering a rapid and flexible channel of dissemination, blogging appears to offer a distinct advantage in the communication, translation and acquisition of these new and necessary skills, experiences and competencies across the profession.

Mclntyre and Nicolle's recommendation in 2008 was timely in suggesting that "as librarians, we can take a leadership role in promoting blog technology as a way of transforming internal communication and external relationships with library users" (p. 688). Today it appears that many librarians have indeed already assumed this mantle, embracing and advocating for the benefits of blogging within our own profession and beyond, and using blogs in innovative ways to promote specific aspects of our services, such as our unique and distinctive collections. Through the ardent and committed participation of such individuals, and the gradual dissemination of this positive experience and passion, it is likely to continue to coax a steady trickle of fellow professionals to join the conversation - in the short term at any rate. It is impossible to know for sure what the long-term future holds in store for blogging. Is it largely a 
function of the times, or will it be embraced by longevity? Blogging does appear to offer a unique and distinct advantage in providing space for broader and deeper communication than many of its rivals, and whilst this aspect survives, it is likely that blogging will too.

\section{References}

Adams, R. (2013). Blogging in context: reviewing the academic library blogosphere. The Electronic Library, 31(5), 664-677.

Barlow, A., Beverley, H. L., Dunham-LaGree, C., Elichko, S., \& Hamstra, E. (2013). Chasing reference: Librarians and collaborative blogging. Reference \& User Services Quarterly, 52(4), 283-286. Retrieved from http://search.proquest.com/docview/1372480630?accountid=9670

Baxter, G. J., Connolly, T. M., \& Stansfield, M. H. (2010). Organisational blogs: benefits and challenges of implementation. The Learning Organization, 17(6), 515-528.

Corcoran, M., \& McGuinness, C. (2014). Keeping ahead of the curve: Academic librarians and continuing professional development in Ireland. Library Management, 35(3),175 - 198.

Dowd, N., Evangeliste, M., \& Silberman, J. (2010). Bite-Sized Marketing : Realistic Solutions for the Overworked Librarian. Chicago, IL, USA: American Library Association Editions. Retrieved from http://www.ebrary.com

Draper, L. \& Turnage, M. (2008) Blogmania, Internet Reference Services Quarterly, 13 (2), 15-55, DOI: 10.1300/J136v13n01_02

Embrey, T. R. (2002). You blog, we blog: A guide to how teacher-librarians can use weblogs to build communication and research skills. Teacher Librarian,30(2), 7.

Fichter, D. (2003). Why and how to use blogs to promote your library's services. Marketing Library Services, 17(6), 1-4.

Guest, G., Bunce, A., \& Johnson, L. (2006). How many interviews are enough? An experiment with data saturation and variability. Field Methods, 18(1), 59-82. 
Hall, H., \& Davison, B. (2007). Social software as support in hybrid learning environments: The value of the blog as a tool for reflective learning and peer support. Library \& information science research, 29(2), 163-187.

Hsieh, H. F., \& Shannon, S. E. (2005). Three approaches to qualitative content analysis. Qualitative Health Research, 15(9), 1277-1288.

Kim, Y. M., \& Abbas, J. (2010). Adoption of Library 2.0 functionalities by academic libraries and users: a knowledge management perspective. The Journal of Academic Librarianship, 36(3), 211-218.

Lee, C., \& Bates, J. (2007). Mapping the Irish biblioblogosphere: Use and perceptions of library weblogs by Irish librarians. The Electronic Library, 25, 648-663. doi:10.1108/02640470710837092

Mallon, M. (2013). Marketing Academic Libraries. Public Services Quarterly,9(2), 145-156.

McIntyre, A., \& Nicolle, J. (2008). Biblioblogging: blogs for library communication. The Electronic Library, 26(5), 683-694.

McQueen, R., \& Knussen, C. (2002). Research methods for social science. New York: Prentice Hall.

Meakin, B. (1981). Communication Skills: The Role of the Library School. Proceedings of the IATUL Conferences. Paper 21. http://docs.lib.purdue.edu/iatul/1981/papers/21

Meho, L. I. (2006). E-mail interviewing in qualitative research: A methodological discussion. Journal of the American society for information science and technology, 57(10), 1284-1295.

Ratzek, W. (2011). The mutations of marketing and libraries. IFLA journal,37(2), 139-151.

Schneider, K. (2005). The Ethical Blogger, Library Journal (April 15, 2005)

Smith, J.A. (1996). Beyond the divide between cognition and discourse: using interpretative phenomenological analysis in health psychology. Psychology and Health, 11(2), 261-271.

Stefanone, M.A. \& Jang, C.Y. (2008). Writing for family and friends: the interpersonal nature of blogs. Journal of Computer Mediated Communication 13 (1) 123 - 140

Stephens, M. (2008). The pragmatic biblioblogger: Examining the motivations and observations of early adopter librarian bloggers. Internet Reference Services Quarterly, 13(4), 311-345.

Stover, J. S. (2007). Making marketing work for your library blog. Internet Reference Services Quarterly, 11(4), 155-167.

Tripathi, M., \& Kumar, S. (2010). Use of Web 2.0 tools in academic libraries: A reconnaissance of the international landscape. The International Information \& Library Review, 42(3), 195-207.

Trivedi, M. (2010). Blogging for libraries and librarians. Library Philosophy and Practice, 1-4. Retrieved from http://search.proquest.com/docview/521635604?accountid=9670 
VanScoy, A. \& Evenstad, S.B. (2015). Interpretative phenomenological analysis for LIS research. Journal of Documentation, 71(2), 338-357. 